\title{
LENDO AS MARGENS DO RIO: ESCRITURA E IDENTIDADE EM CONTEXTOS PERIFÉRICOS
}

\author{
Marcia Lisbôa COSTA DE OLIVEIRA \\ (Universidade do Estado do Rio de Janeiro) \\ lisboamarcia@hotmail.com
}

\begin{abstract}
Resumo: Este ensaio tem por objetivo analisar dois textos escritos em épocas e espaços diversos, que têm em comum o fato de revelarem o ponto de vista de quem vive à margem da sociedade. Articulando a perspectiva dos Novos Estudos do Letramento a reflexões advindas de campos diversos, como a linguística e a crítica literária, tomaremos como ponto axial a relação entre linguagem, sociedade e subjetividade. Nossa proposta é ouvir as vozes das margens, para tentar entender os Discursos e as concepções de letramento e as funções da escrita, que circulam na periferia. Para isso, entreteceremos a leitura do texto autobiográfico "Quarto de Despejo", de Carolina Maria de Jesus, à análise um texto ficcional escrito por um adolescente em situação de vulnerabilidade social. Nessas (auto) representações dos excluídos, buscaremos inferir os valores, comportamentos e atitudes que norteiam suas experiências de vida. Buscaremos entender nesses textos o que eles revelam acerca dos modos de pensar, de ser e de agir dessas de seus autores, cujos discursos primários são, ao menos aparentemente, divergentes daqueles validados pela sociedade e, consequentemente, pela escola. Consideramos que esse trabalho de compreensão dos Outros pode contribuir para que a relação entre a escola e os grupos marginalizados socialmente, ancore-se no reconhecimento da diversidade sociocultural e linguística, sendo pautada pelo diálogo e pelas negociações entre os atores sociais envolvidos no processo de educar-se educando.
\end{abstract}

Palavras-chave: Letramento. Linguagem. Sociedade. Subjetividade.

\section{READING THE RIVER MARGINS: WRITING AND IDENTITY IN PERIPHERICAL CONTEXTS}

\begin{abstract}
This essay aims to analyze two texts written in different times and spaces, which have in common the fact that they reveal the point of view of those who live on the margins of society. Articulating the perspective of the New Literacy Studies to reflections that come from diverse fields such as linguistics and literary criticism, we will take up as a central issue the relationship between language, society and subjectivity. The study is geared towards hearing the voices from the margins, in order to try to understand the discourses and conceptions of literacy, especially regarding the uses and functions of writing, which circulate among those who live and work in the outskirts. In order to do so, we will analyze the book
\end{abstract}


"Quarto de Despejo", written by Carolina Maria de Jesus, and a fictional text written by a teenager in situation of social vulnerability. Reading these (self) representations of the excluded, we will seek to infer the values, behaviors and attitudes that guide their life experiences. We will seek to understand what those texts reveal about their authors' ways of thinking, being and acting, and whose primary discourses are, at least apparently, different from those that get social validation and school validation as well. We believe that this study, while seeking to understand the Other, can contribute to improve the relationship between the school and the socially marginalized groups, based on the recognition of socio-cultural and linguistic diversity, and being guided by dialogues and negotiations among the social actors involved in the process of educating themselves.

Keywords: Literacy. Language. Society. Subjectivity.

\section{Nós somos Outros}

\footnotetext{
“... Nós somos pobres, viemos para as margens do rio. As margens do rio são os lugares do lixo e dos marginais. Gente da favela é considerado os marginais."

Carolina Maria de Jesus (1983, p. 48)
}

Neste texto faremos um exercício de leitura, que é também um exercício de escuta de vozes silenciadas. Vamos ler aqui "as margens do rio" de que fala nossa epígrafe.

Em escritos de Carolina Maria de Jesus e de um adolescente em situação de vulnerabilidade social, tentaremos compreender as subjetividades que se constituem "nas margens do rio", além de alguns valores e concepções sobre a escrita que se instauram nesses territórios.

A voz de Carolina Maria de Jesus em "Quarto de Despejo” (JESUS, 1983), com sua verve politicamente poética, nos convoca a pensar no Outro que ela encarna e no Outro que nós representamos. A Outra voz que escolhemos ouvir neste texto é muito próxima de Carolina, apesar de distante no tempo e no espaço. Trata-se de um jovem que vive à margem do/no Rio de Janeiro. Vamos chamá-lo aqui de José.

José estava em situação de semiliberdade, cumprindo uma medida socioeducativa decorrente do cometimento de uma infração à lei, quando escreveu este conto. Seu texto, que ficcionaliza um diálogo entre mãe e filho, mostra-nos 
como pensa e em que valores acredita, além disso, pelo modo como utiliza a escrita, permite-nos refletir sobre suas concepções de letramento.

Escolhemos dois textos que se situam na fronteira entre o biográfico e 0 ficcional, pois, retomando as palavras de Bakhtin, os gêneros da literatura de ficção são mais propícios à emergência do estilo individual e, portanto, é neles que se pode observar melhor a "expressão da individualidade" (BAKHTIN, 2011, p. 265). Como aqui nos interessa problematizar a expressão subjetiva na linguagem, essa fronteira entre criação e registro parece-nos o espaço textual propício para nossas reflexões.

Pela escrita de Carolina, nós sentimos a angústia da miséria. Pela escrita do adolescente preso, ouvimos o "lado avesso", o lado dos que têm medo. Paradoxalmente, esse jovem marginal é também o Outro que nos causa medo. Ouvi-lo talvez possa ajudar-nos a compreendê-lo.

A escolha do pronome da primeira pessoa do plural é aqui propositalmente significativa. No discurso acadêmico, o plural da primeira pessoa pode ser usado para substituir o singular, criando dois efeitos opostos, a amplificação do "eu" de forma solene e indefinida, quando é empregado o chamado "plural majestático"; ou apenas atenuar a marcação do "eu, pois, "De maneira geral, a pessoa verbal no plural exprime uma pessoa amplificada e difusa (BENVENISTE, 1976, p. 257).

Como apontou Benveniste, as formas pronominais remetem à particularidade de cada enunciação, constituem o que ele chamou de "signos 'vazios', não referenciais em relação à 'realidade', sempre disponíveis, e que se tornam 'plenos' assim que um locutor os assume em cada instância do seu discurso" (BENVENISTE, 2005, p. 280).

$\mathrm{Na}$ língua portuguesa, o pronome NÓS pode ser inclusivo ou exclusivo, dependendo do contexto da enunciação. Ou seja, o pronome pode incluir o interlocutor, significando eu+tu (ou vós), ou pode excluí-lo, significando eu+ele(s) (BENVENISTE, 1976, p. 257).

Neste texto, minha atenção estará voltada, sobretudo, para o jogo de subjetividades que se constitui na linguagem e se estabelece também tanto na produção, quanto na recepção de meu texto. O gênero que aciono, as escolhas linguísticas e as referências que faço neste texto enquanto o escrevo, tudo isso 
seleciona um interlocutor presumível. Crio, assim, um perfil de leitor que assumo como partícipe em uma das camadas dos grupos socioculturais de que participo, a camada acadêmica.

No exercício da linguagem, portanto, assumo-me aqui como locutora e revelo que não pertenço ao mesmo grupo de Carolina e José. Faço o uso inclusivo do pronome, porque você, leitor, faz parte desse Nós.

Eu e você somos NÓS, porque somos também os Outros de Carolina e do jovem à margem do/no Rio. Nós não estamos lá.

Mesmo que seja originário da periferia, na medida em que circula nos corredores universitários, você não ocupa mais esse lugar físico, linguístico e cognitivo, não ocupa mais a mesma posição sociocultural, porque sua identidade hibridizou os discursos primários e secundários com que você conviveu e transformou-se por força dessas interações.

Refletindo sobre os pronomes nós, Helmbrecht afirma que a primeira pessoa do plural sinaliza proximidade e solidariedade, pois:

A participação em grupos sociais precisa ser repetidamente confirmada e comunicada entre os vários membros. Há um grande número de meios linguísticos e extralinguísticos para fazer isso. Os meios linguísticos podem incluir as formas de referência e endereçamento entre membros de uma comunidade. [...] Como esboçamos anteriormente, o uso de pronomes NÓS está intrinsecamente conectado ao estabelecimento de grupos sociais. Os falantes definem explicitamente e publicamente grupos sociais em relação a seus interlocutores usando pronomes NÓS. Ao mesmo tempo, eles afirmam sua participação nesse grupo. Esse é o uso prototípico dos pronomes NÓS. Eles são em si mesmos, portanto, um poderoso meio para estabelecer e reforçar identidades sociais (HELMBRECHT, 2002, p. 42. Tradução nossa). ${ }^{1}$

Dizer nós significa, portanto, colocar-se em um grupo. Os grupos mais estáveis em termos temporais são aqueles aos quais estamos ligados por origem (família, bairro ou localidade, cidade, país), mas além dessa pertença, fazemos parte também de outros grupos mais dinâmicos e plásticos. A nossa identidade se

\footnotetext{
${ }^{1}$ No original: Membership in social groups need repeatedly to be confirmed and communicatedamong the various members. There are a great number of linguistic and extra-linguistic means to do that.Linguistic means may include the forms of reference and adress among the members of an ingroup.[...] As has been outlined above, the use of WE pronouns is intrinsically connected to the linguistic establishment of social groups. Speakers define explicitly and publicly social groups vis à vis their interlocutors by using WE pronouns. At the same time, they state their membership to these groups. This is the prototypical use of WE pronouns. They are therefore, per se a Strong means to reinforce social identities.
} 
estabelece nas interações que desempenhamos nos grupos (HELMBRECHT, 2002, p.31; GEE, 2001-2002).

Os Novos Estudos do Letramento (GEE, 1990; STREET, 2003) que se desenvolveram no campo dos estudos da linguagem nos últimos decênios assumiram uma perspectiva etnográfica e construíram uma perspectiva sociocultural do letramento. As pesquisas desenvolvidas nesse campo investigam as práticas sociais de leitura e escrita particulares de cada grupo social, bem como a natureza ideológica e as relações de poder implicadas nas práticas letradas.

Gee afirma que é nas interações que se constitui o nosso Discurso, utilizando a letra maiúscula para sinalizar que não se trata apenas de nosso modo de usar a linguagem, mas de um conjunto de traços que inclui várias instâncias:

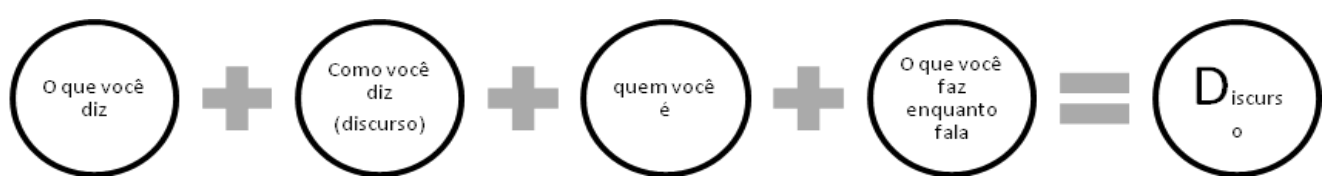

Ou seja, não são apenas as palavras, as estruturas frasais e os gêneros do discurso que utilizamos que demarcam nosso pertencimento a uma comunidade. Embora o modo como utilizamos a língua seja um forte sinal de participação em um grupo, muitos outros traços se conjugam para construir nossas diferentes identidades interacionais.

Para GEE, um conjunto de traços demarca o que ele chama de "identidades particulares":

\begin{abstract}
Discursos são modos de se comportar, interagir, avaliar, pensar, acreditar, falar, e frequentemente de ler e escrever, que são aceitos como instanciações de identidades particulares (ou "tipos de pessoas") por grupos específicos, sejam famílias de um certo tipo, advogados de um certo tipo, ciclistas de um certo tipo, negociantes de um certo tipo, membros da igreja de um certo tipo, afro-americanos de um certo tipo, mulheres ou homens de um certo tipo, e assim por diante, em uma lista muito longa. Discursos são modos de ser 'gente como nós'. Eles são "modos de ser no mundo". Eles são "formas de vida". Eles são identidades sociais situadas. Eles são, portanto, sempre e em todos os espaços produtos de histórias sociais (2012, p. 3. Tradução nossa). ${ }^{2}$
\end{abstract}

\footnotetext{
${ }^{2}$ No original: Discourses are ways of behaving, interacting, valuing, thinking, believing, speaking, and often reading and writing, that are accepted as instantiations of particular identities (or "types of people") by specific groups, whether families of a certain sort, lawyers of a certain sort, bikers of a certain sort, business people of a certain sort, church members of a certain sort, African-Americans of a certain sort, women or men of a certain sort, and so on and so forth through a very long list. Discourses are ways of being "people like us." They are "ways of being in the world"; they are "forms
} 
No caso da academia, a marca que nos permite reconhecer os iguais não está no boné ou na camisa que utilizamos, mas nos comportamentos discursivos e em outras atitudes que nos permitem saber quem são os que participam dessa comunidade de práticas, ou seja, do grupo que compartilha um empreendimento comum e que, engajado nas práticas e nas interações dessa comunidade, é estruturado por ela enquanto o estruturam (WENGER, 1998; ECKERT \& MCCONNELL-GINET, 2010).

Se você está lendo este texto que escrevo, posso inferir que nós compartilhamos as concepções sobre os usos e funções da leitura e da escrita que circulam na universidade, no seio da qual participamos de eventos de letramento muito específicos. Neles, nós lemos e escrevemos para colocar em relação conceitos e modos de usar a linguagem que, pouco a pouco, vão constituindo, não só nossas referências teóricas, mas também nossas concepções sobre 0 letramento nesse contexto acadêmico. Um índice de sua participação nesse grupo, por exemplo, é o fato de estar lendo uma revista científica na área de Letras. Outras atitudes típicas de nosso comportamento leitor já podem ter sido realizadas por você, quando sublinhou trechos, fez anotações ou consultou as referências ao final do texto. NÓs lemos assim.

No trecho que citamos em epígrafe, percebemos que o nós de Carolina não tem o mesmo sentido do pronome quando escrito por mim. Isso fica muito claro em trechos como: "Duro é o pão que nós comemos. Dura é a cama que dormimos. Dura é a vida do favelado" (1983, p.33 Grifo nosso).

Retomaremos agora um dos ensinamentos de Benveniste sobre a natureza dos pronomes que também nos será de grande valia aqui. Trata-se de sua reflexão sobre a terceira pessoa, na qual constata que, em diferentes línguas, este substitutivo "predica o processo de 'não importa o que', 'não importa quem'” (BENVENISTE, 1976, p.282).

Cabe esclarecer que, para o linguista, o termo pessoa identifica os participantes ativos de um ato de enunciação, portanto, somente os pronomes eu e tu carreiam pessoalidade, em sua perspectiva - o pronome ele não assume status de pessoa, neste sentido. Na vida, como na língua, quando dizemos eles, estamos 
nos referindo aos que não são nem o eu locutor, nem o tu, que escuta e, em seguida, toma o turno, na alternância de sujeitos que caracteriza o diálogo.

Será preciso, então, não só na produção desse texto, mas também em sua recepção, manter a vigilância contra a armadilha linguística e, portanto, ideológica, de tratar os sujeitos nas margens dos rios como ELES, objetificando-os.

Podemos começar por algumas indagações: Quem somos nós, os professores, reunidos sob esse signo? Quem são eles, aqueles que conformam o nós de Carolina? Quem são os que vivem à margem do rio, que vivem à margem no Rio?

Por tudo isso, precisamos entender que NÓS somos os Outros deles, assim como ELES são os nossos Outros.

\section{1 - Lendo Carolina}

Daria um filme,

Uma negra,

E uma criança nos braços,

Solitária na floresta,

De concreto e aço,

Veja,

Olha outra vez,

O rosto na multidão,

A multidão é um monstro,

Sem rosto e coração,

Mano Brown, Negro Drama.

Os textos de Carolina Maria de Jesus, editados no livro "Quarto de Despejo", à primeira vista, constituiriam textos da esfera da comunicação cotidiana, configurando, portanto, na perspectiva de Bakhtin, um discurso primário, destinados à esfera privada e, nesse caso, à expressão de seus sentimentos e visões do mundo. No entanto, esses diários, escritos confessionais em que ela registrou para si mesma sua mundivivência, eram ao mesmo tempo, desde a concepção, textos destinados a uma circulação mais ampla. Em diferentes passagens do texto, a narradora reafirma seu ideal de tornar-se escritora e revela as funções que a escrita adquire para ela. 
Com sua verve politicamente poética nos convoca a pensar no Outro que ela encarna e no Outro que nós representamos. Ela expressa a perspectiva dos que se sentem fora da cidade, fora da cidadania:

Às oito e meia da noite eu já estava na favela, respirando o odor dos excrementos que se mescla com o barro podre. Quando estou na cidade tenho a impressão de que estou na sala de visitas com seus lustres de cristais, seus tapetes de veludo, almofadas de cetim. E quando estou na favela tenho a impressão de que sou um objeto fora de uso, digno de estar num quarto de despejo (JESUS, 1983, p. 36).

Ouvi-la é experimentar vicariamente o sofrimento e as sensações de quem percebe na carne a exclusão. Os maus odores e $\mathrm{O}$ grotesco da favela contrastam com a luz e as texturas da cidade e revelam a certeza de sua não-pertença. Carolina está fora, num espaço marcado por indignidade e desigualdade, reservado aos "inúteis". Os territórios da cidade e da não-cidade são metaforizados e "concretizam-se" na alegoria de uma casa dividida, como a sociedade que ela representa: “... Eu classifico São Paulo assim: o Palacio, é a sala de visita. A Prefeitura é a sala de jantar e a cidade é o jardim. A favela é o quintal onde jogam os lixos" (JESUS, 1983, p. 24).

Sem repetir os já cansados epítetos apostos ao nome da escritora, para destacar sua força literária é bom lembrar o lugar a partir do qual ela falava, num período marcado pelo ufanismo estatal, às vésperas do golpe militar de 64. É importante lembrar que foi na extinta favela paulistana do Canindé, no início dos anos JK, que essa mulher "negra e favelada" registrou em cadernos as dores de quem vive a fome.

Sua concepção da escrita como meio de denúncia das agruras de viveR na favela se espalha por vários trechos do livro. Em algumas passagens, ela se coloca como porta-voz dos favelados, como no trecho que destacamos a seguir: “... Aqui na favela quase todos lutam com dificuldades para viver. Mas quem manifesta o que sofre é só eu. Eu faço isso em prol dos outros...

Neste trecho, está implícito o pronome NÓS. O interlocutor de seu texto, nessa e em outras passagens, é alguém que não pertence à favela, alguém que está na "sala de visitas". Ela escreve para que a cidade conheça o sofrimento causado pela fome e pela miséria e saiba o que se passa no "quarto de despejos". 
Consciente da importância de sua voz, ela escreve para ser lida. Seu texto destina-se a um leitor que não pertence ao mesmo universo Discursivo e que, por isso mesmo, talvez ponha em dúvida a veracidade de sua narrativa, assim, ela incorpora ao texto uma possível resposta de seu leitor: Há de existir alguem que lendo o que escrevo dirá ... Isto é mentira! Mas, as miserias são reais" (JESUS, 1983, p.37).

Em outras passagens, ela demonstra seu distanciamento em relação aos habitantes da favela. Nesse aspecto, um traço que se sobreleva no diário é a rigidez do sistema de valores vivido por Carolina. Ela busca a todo tempo reafirmar um sistema ético baseado na retidão do caráter, enfatizando a honestidade, o trabalho e a maternidade como eixos de seu modo de viver. Por isso, condena os hábitos dos seus vizinhos, especialmente o abuso do álcool.

No que tange à maternidade, observamos que ela a todo momento reafirma os filhos como centro de suas preocupações. Daí o destaque atribuído à fome ao longo do texto, ligado ao medo de não ter como alimentar os filhos.

Com base nos princípios que erigiu para criar a imagem de uma vida "modelar", ela julga e condena todos que vivem em torno, especialmente os "bêbados" e as "mulheres fera", que são, em sua visão, "fofoqueiras", maledicentes, grosseiras e violentas. Nos momentos em que se refere a ELAS, Carolina escreve contra a favela e concebe a escrita como denúncia de um cotidiano desumano e cruel, em que os favelados agem como algozes de si mesmos.

Quando as mulheres feras invade meu barraco, os meus filhos Ihes joga pedras. Elas diz:

-Que crianças mal educadas!

Eu digo:

- Os meus filhos estão defendendo-me. Vocês são incultas, não pode compreender. Vou escrever um livro referente a favela. Hei de citar tudo que aqui se passa. E tudo que vocês me fazem; Eu quero escrever o livro, e vocês com essas cenas desagradáveis me fornece os argumentos (JESUS, 1983, p. 17).

Para falar da força da escritura poética de Carolina, dizemos que se trata de uma "escritura apesar de". Apesar da fome, apesar do preconceito racial, apesar do machismo dominante, apesar do pouco acesso à educação, apesar do preconceito da crítica literária, apesar de tudo, ela se expressa e nos mobiliza. Ela constrói seu estilo fundindo palavras duras às delicadas, sofisticações quase parnasianas à linguagem popular e imagens contrastantes de cor e dor. Um exemplo desses 
amálgamas podemos ler na passagem abaixo, escrita em 15 de julho de 1955, que figura na primeira página do diário publicado:

Ablui as crianças, aleitei-as e ablui-me e aleitei-me. Esperei até as 11 horas, um certo alguem. Ele não veio. Tomei um melhoral e deitei-me novamente. Quando despertei o astro rei deslisava no espaço. A minha filha Vera Eunice dizia: - Vai buscar água, mamãe! (JESUS, 1983, p.9).

Neste trecho, a sofisticação vocabular da narradora autodiegética contrasta com os "erros" de grafia, ao mesmo tempo em que o uso da ênclise denota o esforço para escrever a língua dos dominantes, "fingindo ser", ela também, dominante. Assim, constroi um discurso de fronteira (GEE, 2012), hibridizando formas que ela identifica como "literárias" ao seu discurso familiar-comunitário.

Essa peculiaridade da escritura de Carolina e a temática de seus cadernos foram saudadas como grande novidade por ocasião da publicação do livro "Quarto de Despejo", editado pelo jornalista Audálio Dantas. No contexto, a entrada de uma mulher-negra-favelada no panteão literário nacional já era, por princípio, a criação de uma exceção, como revela Regina Dalcastagnè acerca de um período posterior, nada diferente no cenário das letras brasileiras:

Tal como outras esferas de produção de discurso, o campo literário brasileiro se configura como um espaço de exclusão. Nossos autores são, em sua maioria, homens, brancos (praticamente todos), moradores dos grandes centros urbanos e de classe média - e é de dentro dessa perspectiva social que nascem suas personagens, que são construídas suas representações. Conforme mostra uma ampla pesquisa sobre a totalidade dos romances publicados pelas principais editoras do País nos últimos 15 anos, a homogeneidade dos autores se reflete em suas criações. O outro (mulheres, pobres, negros, trabalhadores) está, em geral, ausente; quando incluído nessas narrativas, costuma aparecer em posição secundária, sem voz e, muitas vezes, marcado por estereótipos (DALCASTAGNË, 2007, p. 1).

No entanto, ou talvez por isso mesmo, as obras de Carolina também foram muito incompreendidas. Essa incompreensão estava associada a diferentes processos. Um deles é fato de que o assunto de seus cadernos, publicado em revista de grande circulação, atraiu logo a atenção do circuito midiático, impulsionando a venda de milhares de exemplares do livro e sua tradução em mais de uma dezena de línguas. Mas essa atenção de parte de um público acostumado à velocidade das informações, além de ter sido passageira, não provocou um verdadeiro envolvimento humanitário com as questões que ela coloca em sua obra. 
Outro aspecto de sua recepção, talvez mais forte que o primeiro, foi o "exotismo" com que foi recebido esse discurso que emergia da "barbárie", de onde não se esperava racionalidade (nem crítica). Em seus textos, encontramos análises duras da nossa sociedade, com clareza e simplicidade, quase em aforismos, como os trechos que citamos a seguir, os quais nem sempre foram bem vistos, afinal, ela mostra um viés muito diverso do senso comum quando afirma a fome como uma categoria que favorece o desenvolvimento de uma Outra racionalidade:

“... O Brasil precisa ser dirigido por uma pessoa que já passou fome. A fome também é professora.

Quem passa fome aprende a pensar no proximo, e nas crianças".

Para mim, o mundo em vez de evoluir está retornando a primitividade. Quem não conhece a fome há de dizer: "Quem escreve isto é louco. Mas quem passa fome há de dizer:

- Muito bem, Carolina. Os generos alimentícios devem ser ao alcance de todos (JESUS, 1983, p. 22 e 30).

Após o sucesso inicial, funcionou em relação a ela a mesma força de censura que cala milhões de brasileiros, tratados como "sem língua", os que "não sabem nem falar". No campo da crítica literária, houve quem afirmasse que seus erros" não cabiam na literatura, ou que seu texto era bem escrito demais para ter sido escrito por uma favelada. Houve ainda aqueles que viram em seu estilo oscilações entre a norma e o erro que "soavam artificiais".

Em todas essas vozes, falavam os dominantes, acostumados ao exercício do poder, tentando calar os que, sendo dominados, resistem.

\section{2 - Lendo José}

E pobres são como podres e todos sabem como se tratam os pretos. Caetano Veloso (Haiti)

O texto que reproduziremos a seguir foi escrito por um adolescente em uma oficina do Projeto Letrajovem (UERJ-FFP/DEPEXT - CETREINA/FAPERJ).

Para procedermos à análise, faremos a transcrição, respeitando a linguagem empregada, dividindo o texto em stanzas, que segundo Gee, são universais e 
constituem o produto dos mecanismos mentais pelos quais os homens produzem a fala (GEE, 1999 e 2012). Assim, seccionaremos a narrativa em sequências de linhas dedicadas a um só tópico, para identificar as estratégias discursivas empregadas e os valores predominantes em cada um dos segmentos.

A primeira stanza, que inclui o título, situa o leitor em relação aos fatos narrados. É nessa parte que fica configurada a máscara ficcional empregada pelo narrador, que conta em primeira pessoa uma cena da qual não participa, No título é acentuado o vínculo com a realidade, mas também é sinalizado o processo de recriação do real, uma vez que a cena narrada já não é mais o real em si, mas uma representação nele baseada. Os personagens que entrarão em diálogo também são apresentados nesse trecho:

\section{Stanza 1- Contextualização}

Basiado em fatos reais

"Uma vez num dia meu irmão numa conversa com minha mãe, falou:

Os personagens que entrarão em diálogo também são apresentados nesse trecho. Na sequência, o filho inicia o diálogo, questionando a mãe. Nessa passagem, temos a afirmação da vida no crime como algo que já constitui sua identidade, daí que ele questione o porquê das reclamações da mãe.

\section{Stanza 2 - Reclamação e sobrevivência}

O mãe porque sempre você fala e reclama da minha vida e do meu jeito de ser, parece até que não conhece o filho que tem porque já não é de hoje que estou nessa vida e tantos anos já to vivendo na vida do crime e sobrevivendo assim não sei se posso sai,

Na segunda stanza, o verbo sobreviver é bastante significativo, pois sabemos que os jovens envolvidos com o crime costumam morrer cedo. Ao afirmar que está sobrevivendo há anos "nessa vida", o personagem reafirma seu pertencimento a uma "comunidade de práticas" que está tão marcada em sua experiência que já caracteriza seu "jeito de ser". Podemos pensar que ele, nessa parte do texto, ele vincula sua identidade ao Discurso do crime, com seus modos de agir, falar e pensar. 
O motivo da dúvida expressa em "não sei se posso sai[r]" será explicitado nas duas stanzas seguintes, que funcionam como justificativa para a adesão à "comunidade do crime", mas também revelam outros valores importantes para a compreensão das tensões que se estabelecem na configuração das múltiplas identidades construídas nas formas de interação social:

Stanza 3 - Medo da necessidade

mas tenho medo de passa necessidade vivendo como trabalhador, e poriso que até hoje eu estou nessa vida não acho força para sai do crime, na minha casa não falta nada dota [toda] semana compro as coisas pra dentro de casa meus filhos tem de tudo, nada falta para eles brinquedos, roupas, escola etc...

Poriso tenho muito medo de sai do crime, eu só vivo no crime por necessidade não é por sucesso nem por fama;

Destacamos na transcrição os operadores de coesão, que revelam a contradição entre a ideia de sair do crime e a explicação de sua permanência. No início desse texto, afirmamos que, aparentemente o discurso dos dois textos analisados se contraporia àquele validado pela sociedade. A seguir verificaremos que, na verdade, como já ocorrera no texto de Carolina, José reafirma valores fundamentais para a vida em sociedade, embora por um ponto de vista bastante diverso daquele pelo qual Nós costumamos enxergar a realidade.

Em primeiro lugar, destacamos que o emprego do termo "trabalhador" revela respeito, e não desprezo por essa categoria. Quando ele afirma que "não acha força para sai[r]" do crime, podemos inferir que há um contraponto entre o trabalho, que exige força, e o crime, que atende às necessidades imediatas. Ou seja, está implícita a ideia de que os fortes trabalham, enquanto os fracos permanecem no crime.

Na terceira stanza, há um traço que demonstra o quanto tal contradição é apenas aparente, pois os valores marcados aqui estão relacionados à família. Assim como no caso de Carolina, também José vai enfatizar os filhos como eixo de suas preocupações, uma vez que para garantir que eles tenham acesso aos bens de consumo, o personagem permanece no crime.

Levantando a máscara ficcional que é construída na narrativa, é curioso notar que a paternidade assume grande valor para esse adolescente, fato que também 
demarca sua pertença à "comunidade do crime". Isso porque, talvez pela certeza de que morrerão cedo, é comum que os adolescentes em situação de conflito com a lei sejam pais muito cedo, na maioria das vezes tendo filhos em diferentes relacionamentos.

Se as estatísticas revelam que a gravidez na adolescência é cada vez mais comum nas camadas populares, entre os jovens envolvidos com o crime, ela se torna um valor. Para ELES, ter um filho significa afirmar a masculinidade e garantir sua permanência, deixando sua marca. A paternidade é também, simbolicamente, um signo da entrada na vida adulta.

No texto, os filhos funcionam como justificativa para a permanência no crime, mas também revelam outros valores importantes para a compreensão das tensões que se estabelecem na configuração das múltiplas identidades construídas na interação social. Ao afirmar que os filhos têm tudo, ele destaca alimentos, brinquedos, roupas e escola. Ou seja, há aqui uma forte valorização da família nuclear burguesa e dos atributos da infância, com destaque para o acesso à escola, ao contrário do que NÓS poderíamos supor, com base na visão cristalizada que construímos dos "marginais".

A palavra medo, repetida quatro vezes, é um elemento semântico importante. O medo da fome de que fala Carolina reaparece aqui de outra forma. Há o medo de "passar necessidade" e o medo de morrer, reiterados no texto.

A afirmação de que está no crime por necessidade, "não por fama", é mais uma marca de participação na "comunidade do crime", na qual os diferentes níveis de participação e envolvimento no gerenciamento das ações criminosas geram status. Esse status se alonga de dentro para fora da comunidade de práticas. Ser "gerente" ou "dono do morro é uma posição almejada pelos adolescentes, que lhes garante o respeito da comunidade mais ampla, a vizinhança, que, talvez mais por temor do que por admiração, trata com distinção os "famosos".

NÓS, que estamos fora das interações que ocorrem entre a "comunidade do crime" e sua vizinhança, temos dificuldade de entender a que ele se refere quando fala em fama. O mesmo ocorre em relação ao sentido da expressão "viver bem", na stanza 4. 
$\mathrm{Na}$ passagem destacada abaixo, os sentimentos de medo e arrependimento são contraditórios, como marca a conjunção mas, empregada duas vezes neste trecho:

\section{Stanza 4 - Medo de morrer}

E mãe, mas em todos esses anos procurando viver bem não consigo encontra paz não durmo direito nem tenho paz na minha vida, mas eu quero muda de vida tenho que encontrar forças pra sai da vida do crime, eu tenho medo de morre deixa meus filhos passando por necessidade e disso tudo que eu tenho medo mãe,...

A oposição entre "viver bem" no sentido material e no sentido espiritual fica bem marcada acima e prepara a transição entre o desejo de "mudar de vida" e o pedido de perdão que será feito na stanza seguinte.

\section{Stanza 5 - Vergonha}

- mãe me perdoa por ser a vergonha da família, não ter seguido seus concelios e ter ido pra vida do crime ter errado tanto tempo e agora não tenho paz,

A mãe é uma figura idealizada que representa a moral cristã, cujo dualismo pecado/ virtude pode ser observado no fundo semântico de todo o diálogo. A ideia de família é retomada através da figura materna, agora associada ao perdão, o que é extremamente significativo no plano ideológico do texto, em que a mãe representa o bem e a redenção pelo amor:

Stanza 4 - Lição e redenção

- É meu filho, tanto tempo eu ti falei pra sai dessa vida você só perdeu tempo e agora tu não tem paz e eu ti pergunto meu filho sera que faleu a pena todos esses anos sua vida sem paz e dinheiro não e tudo na vida meu filho eu te amo só quero seu bem...

Nas palavras da mãe, observamos o imaginário cristão materializado nas oposições que representam o eterno duelo entre a carne e o espírito: crime x paz; dinheiro $x$ amor.

No que tange ao foco narrativo, como já afirmamos, há um narrador em primeira pessoa que não participa da história como personagem, mas, à medida que o diálogo progride, a fusão entre o narrador e o personagem também aumenta progressivamente. Dessa forma, quando o "irmão" diz EU, identificamos a voz de um personagem/narrador e a persona criada na narrativa assume o centro da cena. 
$\mathrm{Na}$ medida em que o amálgama identitário que caracteriza a subjetividade não se constitui como um bloco coeso, é a linguagem que permite o afloramento de diferentes aspectos da identidade. No segundo movimento do texto, formado pelas stanzas 4, 5 e 6, observamos que são reafirmados valores marcantes da sociedade ocidental, como o respeito à figura materna, o papel do pai como provedor e a valorização cristã dos aspectos espirituais sobre os materiais.

Gee fala em quatro formas de conceber a identidade, identidade natural, identidade discursiva, identidade discursiva e identidade por afinidade. Todas elas co-existem na sociedade contemporânea em torno da identidade nuclear. No discurso do personagem, encontramos traços da identidade por afinidade com a "comunidade do crime", que se superpõem a traços de sua identidade institucional como preso e à identidade discursiva que ele constrói na enunciação. No entanto, parece-nos difícil assinalar uma propensão natural ao crime que pudesse caracterizar sua identidade natural.

Como Carolina, José escreve para ser lido. A escrita ficcional tem aqui a função de, pelo processo de fingimento, endereçar aos potenciais leitores, pela via da persona narrativa, uma visão positiva do autor. Considerando-se a situação prisional vivida por ele, podemos inferir que o discurso é aqui manipulado como uma peça de auto-defesa, em que a confissão, o arrependimento e o perdão completam o ciclo da redenção desejada. 


\section{Considerações finais}

Nossa voz ta no ar

Por mais que eu tenha espírito de mudança vejo contradições que me causam desesperança

Cansa ver tanta gente ignorante

Tratando gente humilde de forma arrogante

Deselegante ao lidar com a maioria

Que fala com sotaque de periferia

$\mathrm{Na}$ correria, sobrevivendo a covardia

Daqueles que nos retribui com antipatia

(MV Bill. Causa e efeito)

Para nos ajudar a pensar sobre o fato de pertencermos a grupos sociais diferentes e sobre os desafios ideológicos e dialógicos que precisaremos enfrentar para romper a barreira entre aqueles que incluímos quando usamos o pronome nós e aqueles que excluímos usando o pronome eles, será preciso articularmos diferentes perspectivas sobre as relações entre linguagem, sociedade e ensino.

Parece-nos fundamental refletir acerca das questões ideológicas implicadas na nas relações entre diferentes grupos socioculturais, para que possamos pensar na garantia do direito à educação de todos os brasileiros. No aspecto específico do letramento - foi a capacidade de usar e de recriar a escrita para dizer-se e dizer o mundo que possibilitou a expressão de Carolina e de José.

Por outro lado, os limites de seu acesso aos bens culturais e da circulação de seus textos no âmbito da chamada "cultura letrada" são definidos também pelas limitações de seus conhecimentos no que se refere ao sistema da escrita. São tais limitações que fazem recair sobre seus textos o peso do preconceito, afinal, "ELES nem sabem escrever corretamente."

O domínio das estruturas narrativas revelado no texto de José, o qual contrasta com suas habilidades no que concerne às convenções do sistema da escrita, demonstra que o letramento narrativo é muito mais presente no cotidiano de diferentes grupos sociais do que o letramento dissertativo, que é predominante na escolarização formal. É por isso que esse segundo tipo de letramento assume 
posição dominante, já que representa de maneira "neutra" o modo de pensar das classes que detêm o poder na sociedade.

Já no caso de Carolina, o que incomodou foi exatamente sua capacidade de mesclar narração e argumentação, assumindo o discurso dos que a subjugavam. Como ela não apresenta o domínio das convenções de escrita, esse foi o ponto de desconstrução escolhido pelos setores mais conservadores da crítica.

Ambas as narrativas estão abertas ao diálogo com o Outro e projetam atitudes responsivas na escolha dos recursos estilístico-composicionais de que lançam mão. A escritura de José procura influenciar as convicções do leitor e busca no diálogo reencenado obter o seu perdão. Para Carolina, a função da escrita de si-mesma assume uma forma diferente, pois ela usa a linguagem para modificar as concepções de seu leitor implicado, que está fora da favela. Ao revelar um ponto de vista interno sobre esse território marginal, seu "diário" ficcional prevê uma atitude responsiva que assume a forma de uma "influência educativa sobre seus leitores" (BAKHTIN, 2011, p. 279).

$\mathrm{Na}$ análise das narrativas selecionadas, procuramos escapar à objetificação do Outro que se processa no uso dos pronomes de terceira pessoa e se torna um índice dos processos sociais de exclusão que a língua também demarca.

Acreditamos que ler e ouvir os Outros, ser lido e ouvido pelos Outros poderia instalar na educação a responsividade que caracteriza o diálogo, ajudando-nos a recuperar o sentido de coletividade que se materializa linguisticamente no pronome NÓS. Esse poderia ser o início do caminho em direção à recuperação de nossa humanidade, pela abertura à humanidade do Outro que, nesse texto, corporificamos em Carolina e José.

Assim, um passo para entender a humanidade que se instala às margens dos rios seria deixarmos de falar que eles são violentos, que eles não sabem nada, que eles não sabem falar, que eles não entendem nada, que eles são maleducados, que eles, em suma, são bárbaros, para escutá-los.

Para recuperar o sentido da humanidade nas margens, em vez de julgar e excluir, precisaremos entender a diversidade como categoria que funda o humano. NÓS, os humanos somos variados, complexos, distintos, peculiares. Nós temos distintas concepções sobre as funções da leitura e da escrita, nós vivemos valores 
ricamente diversos e esse deveria ser o fundamento de uma educação plenamente democrática.

\section{Referências}

BAKHTIN, M. Os gêneros do discurso. In: BAKHTIN, M. Estética da criação verbal. São Paulo: Martins Fontes, 2011.

BARTON, David e HAMILTON, Mary. Literacy practices. In: BARTON, David; HAMILTON, Mary \& IVANIČ, Roz. Situated literacies; Reading and writing in context. London/New York: Routledge, 2000.

BENVENISTE, Émile. Problemas de linguística geral I. São Paulo: Editora Nacional/EDUSP, 1976.

DALCASTAGNĖ, Regina. A auto-representação de grupos marginalizados: tensões e estratégias na narrativa contemporânea. Letras de Hoje. Porto Alegre, v. 42, n. 4, p. 18-31, dezembro:2007.

ECKERT, P.; MCCONNELL-GINET, S. Comunidades de práticas: lugar onde coabitam linguagem, gênero e poder (1992). In: OSTERMANN, A. C.; FONTANA, B. (Org.). Linguagem, gênero, sexualidade: clássicos traduzidos. São Paulo: Parábola, 2010.

GEE, James Paul. An introduction to discourse analysis; theory and method. London and New York. 1999.

. Identity as na analytic lens for research in education. Review of Research in Education, v. 25, p. 99- 125, 2000-2001.

Social linguistics and literacies; ideology in discourses. 4. ed. New York: Routledge. 2012.

HELMBRECHT, Johannes. Grammar and function of we. In: DUSZAK, Anna. (ed.) Us and Others: social identities across discourses and cultures. Philadelphia: John Benjamins, 2002.

JESUS, Carolina Maria de. Quarto de despejo: diário de uma favelada. 10. ed. Rio de Janeiro: Francisco Alves, 1983.

STREET, Brian V. Letramentos sociais. Abordagens críticas do letramento no desenvolvimento, na etnografia e na educação. São Paulo: Parábola, 2014.

WENGER, E. Communities of practice; learning, meaning and identity. Cambridge: Cambridge University Press, 1998. 
Artigo recebido em: 03 de agosto de 2015

Artigo aprovado em: 02 de setembro de 2015

\section{Sobre a autora:}

Marcia Lisboa Costa de Oliveira é Doutora em Letras (Ciência da Literatura) pela Universidade Federal do Rio de Janeiro (2002). Mestre em Letras (Ciência da Literatura) pela mesma universidade (1995). Professora da Universidade do Estado do Rio de Janeiro, atuando na Faculdade de Formação de Professores, no Departamento de Letras. Membro do corpo docente do Mestrado Profissionalizante em Letras - PROFLETRAS e da Especialização em Estudos Literários na FFP/UERJ. Coordenadora do projeto de Extensão "Letrajovem: oficinas de Língua Portuguesa para Jovens e Adultos em Situação de Conflito com a Lei", realizado em convênio com o Departamento de Acompanhamento de Projetos Especiais do Tribunal de Justiça do estado do Rio de Janeiro e em parceria com o Centro de Recursos Integrados de Atenção ao Adolescente de São Gonçalo. Tem experiência em projetos de Letramento Literário e desenvolve pesquisas sobre letramento e inclusão social. Atua principalmente nos seguintes temas: leitura e formação de leitores, letramento de jovens e adultos, metodologia do ensino de língua portuguesa e formação de professores. Membro (pesquisador) do Grupo de Pesquisa Linguagem \& Sociedade (FFP/UERJ-CNPq). 